\title{
REMOVAL OF Cr(VI), Pb(II), Mn(II) and Bi(III) FROM AQUEOUS SOLUTIONS USING GRANULAR ACTIVATED CHARCOAL PREPARED FROM Cordia Macleodii TREE BARK
}

\author{
A.K. Wanjari* and U. E. Chaudhari \\ Department of Chemistry, Mahatma Fule Arts, Commerce and Sitaramji Chaudhari Science \\ College, Warud, Sant Gadge Baba Amravati University, Maharashtra, INDIA \\ *E-mail: atulrdik@gmail.com
}

\begin{abstract}
This paper reports the results of the study on the performance of low-cost adsorbent such as granular activated charcoal (GAC) and surface modified granular activated charcoal with Sodium dodecylbenzenesulfonate (SDBS), Dioctyl sodium sulfosuccinate (DOSS), Sodium dodecyl sulfate (SDS)in removing Cr (VI), Pb (II), Mn (II) and Bi (III) from aqueous media.The continuous tests were conducted at constant flow rates and bed height. The study were carried out by using initial concentration $21.25 \mathrm{mg} / \mathrm{l}, 30.75 \mathrm{mg} / \mathrm{l}, 19.77 \mathrm{mg} / \mathrm{l}, 20.43 \mathrm{mg} / \mathrm{l}$ having $\mathrm{pH}$ 2, 5, 11.5 and 1 for $\mathrm{Cr}$ (VI), $\mathrm{Pb}$ (II), Mn (II), Bi (III) metal ions respectively. Among the various surfactant tested to increase the adsorption capacity of GAC, GAC-loaded with SDS effectively removed the toxic metal ions from aqueous media. It was concluded that the GAC-loaded with SDS was an effective low-costadsorbent for the removal of metal ions from aqueous solutions.
\end{abstract}

Keywords: Adsorption, Chromium, Lead, Manganese, Bismuth, Column study, Water pollution

○ RASĀYAN. All rights reserved

\section{INTRODUCTION}

Removal of toxic metal ions from contaminated water can be done by various techniques like chemical precipitation, ion exchange; sedimentation etc ${ }^{1-4}$. These techniques require economically high investment and running cost and are also ineffective in low strength wastewaters ${ }^{5}$. The adsorption technique is economically feasible and widely employed for the removal of toxic metal ions from wastewater because of advantages such as applicability, flexibility in terms of choice of adsorbent and high removal efficiencies. Many investigators used batch method for this purpose. The actual practical approach involves the studies in continuous operations. For this column study has various advantages such ease of operation, flexibility, cost effectiveness and design ${ }^{6}$. Many researchers focus on low-cost adsorbent material for the removal of heavy metal ions from wastewater for this purpose activated carbon is wellknown adsorbent and very effective for the removal of heavy metals, dissolve substances etc because of its high surface area and porosity ${ }^{7}$. Zinc and Nickel are also common pollutants which causea headache, nausea, and vomiting. These heavy metals are removed by using Syzygium aromaticum ${ }^{8}$. Organic dyes are an integral part of many industries, these dyes polluted the water. To remove this dyes waste aquacultural shell powders are used ${ }^{9}$.

The present study sought to investigate granular activates charcoal prepared from CordiaMacleodii tree bark as an alternative low-cost adsorbent. The objectives were to perform column studies to investigate the Chromium (VI), Lead (II), Manganese (II), Bismuth (III) uptake characteristics from aqueous solution on GAC and surface modified GAC at constant flow rate.

\section{Preparation of Adsorbent}

\section{EXPERIMENTAL}

Granular activated charcoal was prepared from CordiaMacleodii tree bark. The tree was found to be road side of pusla village, Amravati district, Maharashtra state, India. The collected bark washes with 
deionized water to removes any mud present on the surface of the bark then dried in the sunlight. Prepared raw adsorbent converted into granular activated charcoal by using muffle furnace.

\section{Activation of Adsorbent}

The prepared granular activated charcoal (GAC) was further activated with water and nitric acid in 1:1 proportion to increase the porosity of GAC. For activation to the 10 gram of GAC $100 \mathrm{ml}$ of $\mathrm{H}_{2} \mathrm{O}+\mathrm{HNO}_{3}$ in 1:1 proportion were added and stir for about $48 \mathrm{Hr}$ at RT. The acid treated adsorbent was thoroughly washed with hot distilled water to remove acidity. The product was finally dried and used as an adsorbent.

\section{General Procedure}

Surface Modification of adsorbent

Functional groups present on the surface of the adsorbent plays avital role in the adsorption capacity of prepared adsorbent.Higher capacity adsorbent i.e. GAC its surface was modified by using anionic surfactants as chelating agents like Sodium dodecyl benzene sulfonate (SDBS), Dioctyl sodium sulfosuccinate (DOSS), Sodium dodecyl sulfate (SDS). Surface modification was done by taking $200 \mathrm{ml}$ solution of achelating agent $(0.01 \mathrm{M})$ and 0.5 gram of adsorbent in reagent bottle and shaken for 3 hours at $1000 \mathrm{rpm}$ at room temperature, then dried in an oven. The resultant loaded granulated activated charcoal with Sodium dodecyl benzene sulfonate, Dioctyl sodium sulfosuccinate, Sodium dodecyl sulfate designated as GAC-SDBS, GAC-DOSS, and GAC-SDS.

\section{Preparation of stock solution}

For Source of $\mathrm{Cr}(\mathrm{VI}), 0.0001 \mathrm{M}$ of $\mathrm{K}_{2} \mathrm{Cr}_{2} \mathrm{O}_{7}$ was prepared as a stock solution.Chromium was estimated by 1, 5-Diphenyl Carbazide method and the absorbance of the purplecolor complex was measured at $540 \mathrm{~nm}$. The lead was estimated by Dithizone method and absorbance of the cherry red color complex was measured at $480 \mathrm{~nm}$. Lead nitrate solution $0.01 \mathrm{M}$ was prepared by dissolving 3.312 grams of Lead nitrate in 1 liter double distilled water. An aliquot $10 \mathrm{ml}$ of the $0.01 \mathrm{M}$ solution diluted to 1 liter double distilled water and used as a stock solution. Manganese was estimated by Periodate method and the absorbance of the purple color complex was measured at $460 \mathrm{~nm}$. 0.01M solutions of Manganese Bromide was prepared by dissolving 0.28 grams of Manganese Bromide in 1 liter double distilled water. An aliquot $10 \mathrm{ml}$ of the $0.01 \mathrm{M}$ solution diluted to 1 liter double distilled water and used as a stock solution. Bismuth was estimated by Hypophosphorous acid method and the absorbance of the yellow color complex was measured at $460 \mathrm{~nm}$. Standard solution of $\mathrm{BiCl}_{3}(0.005 \mathrm{M})$ was prepared by dissolving 1.5767 grams of Bismuth trichloride in one liter of double distilled water. By using these solutions absorbance was measured by spectrophotometrically.

\section{Column Study}

Column studies were carried out in a glass column of $20 \mathrm{~mm}$ internal diameter and $50 \mathrm{~cm}$ height. Studies were carried out for the retrieval of $\mathrm{Cr}$ (VI), $\mathrm{Pb}$ (II), Mn (II) and Bi (III). In the bottom side, $0.5 \mathrm{~cm}$ thick glass wool was placed to prevent any loss of adsorbent. To this column, 5 gram of adsorbent were added. The total experiment was carried out at room temperature. The flow rate was adjusted at $3 \mathrm{ml} / \mathrm{min}$.

Once the column was ready, $500 \mathrm{ml}$ solution of $\mathrm{Cr}$ (VI) having concentration $21.25 \mathrm{mg} / \mathrm{L}$ at its particular $\mathrm{pH}$ was taken in each of the separating funnel attached to the respective column and allowed to flow through the column, at flow rate $3 \mathrm{ml} / \mathrm{min}$. The sample was collected after passing through the column and analyzed for metal ions content spectrophotometrically at a particular wavelength. The Same experiment was carried out for $\mathrm{Pb}$ (II), $\mathrm{Mn}$ (II) and $\mathrm{Bi}$ (III) at its particular $\mathrm{pH}$ results are shown in figure no. 1, 2, 3 and 4.

\section{RESULTS AND DISCUSSION}

Heavy metals are hazardous to living and non-living organisms if they exist the maximum permissible limit. So it is important to removal this heavy metal ion from wastewater. The present study deals with the removal of $\mathrm{Cr}$ (VI), $\mathrm{Pb}$ (II), Mn (II) and $\mathrm{Bi}$ (III) metal ions from aqueous solutions. The granular activated charcoal and surface modified granular activated charcoal successfully employed for the 
retrieval of $\mathrm{Cr}$ (VI), $\mathrm{Pb}$ (II), Mn (II) and $\mathrm{Bi}$ (III) metal ions by column method. Column method is economically feasible and successfully carried out by using GAC and impregnated GAC with DOSS, SDBS, SDS for the removal of heavy metal ions.

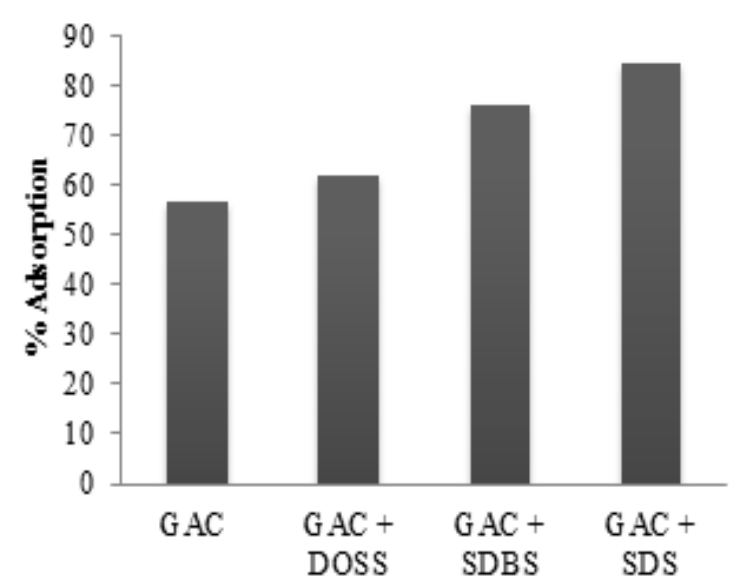

Fig.-1: Effect of column study for removal of Cr (VI)

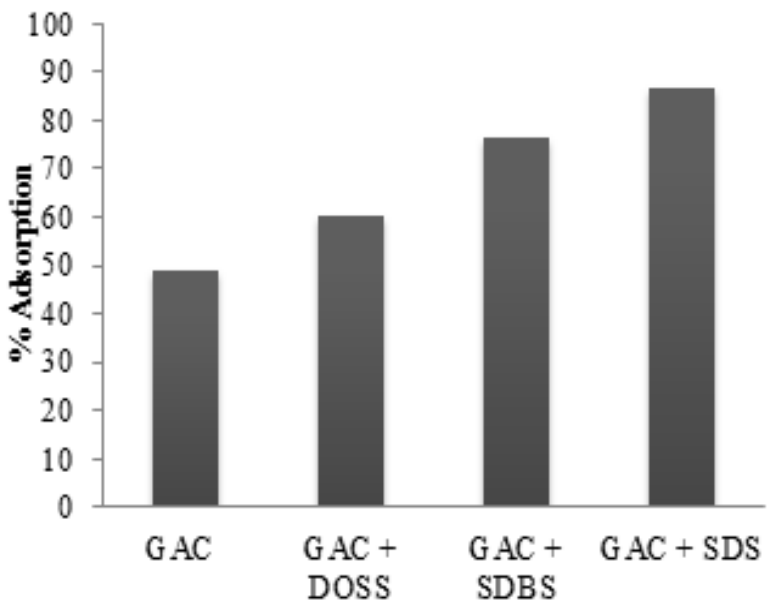

Fig.-3: Effect of column study for removal of Mn (II)

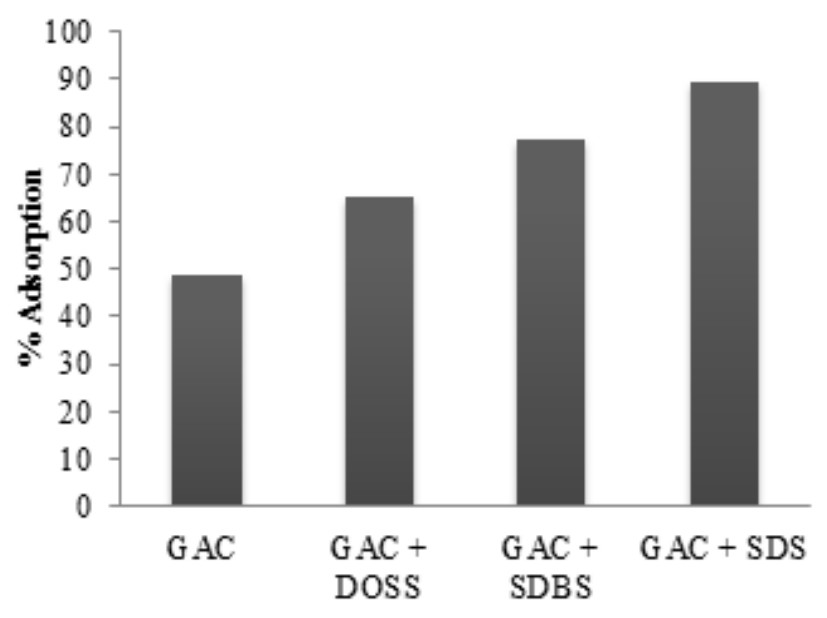

Fig.-2: Effect of column study for removal of $\mathrm{Pb}$ (II)

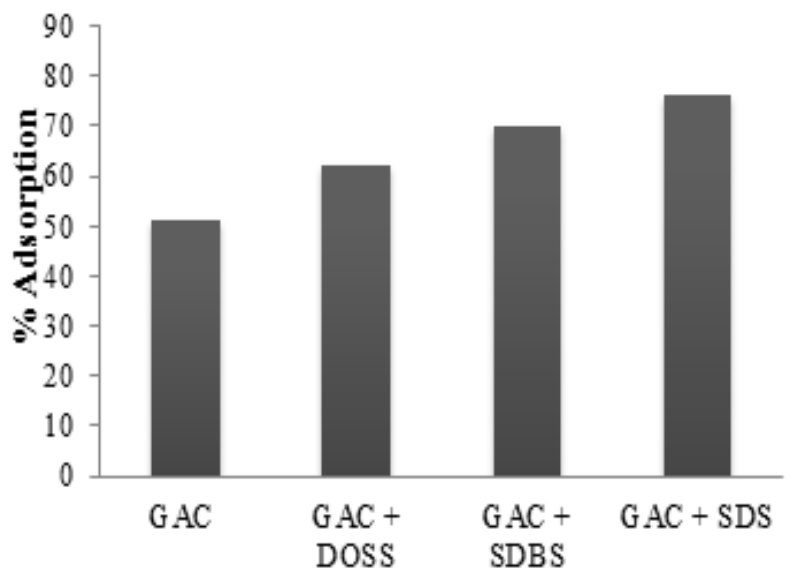

Fig.-4: Effect of column study for removal of Bi (III)

\section{CONCLUSION}

This study showed that the granular activated charcoal and impregnated granular activated charcoal could be used aseconomically cheap and low-cost efficient adsorbent for the retrieval of $\mathrm{Cr}$ (VI), $\mathrm{Pb}$ (II), $\mathrm{Mn}$ (II) and Bi (III) metal ions from aqueous solutions. The experimental data obtained from the study showed that impregnated GAC with DOSS, SDBS, and SDS are more effective adsorbent than virgin granular activated charcoal to removal $\mathrm{Cr}$ (VI), $\mathrm{Pb}$ (II), Mn (II) and $\mathrm{Bi}$ (III) metal ions from synthetic aqueous solution. The removal capacity of metal ions from aqueous media strongly dependent on the flow rate and bed height. Among the three surfactants tested as chelating agents with granular activated charcoal, GAC-loaded with SDS effectively removes the $\mathrm{Cr}$ (VI), $\mathrm{Pb}$ (II), Mn (II) and Bi (III) metal ions. The percentage of adsorption of $\mathrm{Cr}$ (VI), $\mathrm{Pb}$ (II), Mn (II) and $\mathrm{Bi}$ (III) metal ions were found to be 84.26 $\%, 89.43 \%, 86.46 \%$ and $76.30 \%$ respectively by using GAC-loaded with SDS adsorbent. 
RASĀYAN $J$. Chem.

Vol. 10 | No. 1 |82-85 | January - March | 2017

\section{ACKNOWLEDGEMENT}

Authors are very much thankful to Dr. D.V. Atkare, Principal of Mahatma Fule Art's, Commerce and Sitaramji Chaudhari Science College Warud, for providing necessary facilities to carry out the research work.

\section{REFERENCES}

1. M.Ajmal, A.H. Khan, S. Ahmad,Water Res.,32, 3085 (1998).

2. G.Donmez, Z. Aksu, Proc. Biochem.,35,135 (1999).

3. B. Yu, Y. Zhang, S. S. Shukla,J. Hazard.Mater.80,33 (2000).

4. J.Virkutyte, E.Hullebusch, M.Sillanpëë, P. Lens, Environ. Pollution, 138,517 (2005).

5. K.Vijayaraghavan, K.Palanivelu, M.Velan, Process Biochemistry, 41(4),853 (2006).

6. S.J. Kulkarni, J.P. Kaware, International Journal of Research, 1(6),861 (2014).

7. L.Droste, L. Ronal, Theory and Practice of Water and Wastewater Treatment. New York: John Wiley and Sons, Inc. p.523 (1997).

8. A. Masood, A. Mohd, R. Sumbul, Rasayan Journal of Chemistry, 2(4), 791(2009).

9. T. Santhi, S. manonmani, T. Smitha, K. Mahalakshmi, Rasayan Journal of Chemistry, 2(4), 813 (2009).

[RJC-1556/2017] 